\title{
The causes, consequences, and mediating effects of job burnout among hospital employees in Taiwan
}

\author{
Yea-Wen Lin \\ Department of Healthcare Management, Yuanpei University, Hsinchu, Taiwan \\ Correspondence: Yea-Wen Lin. Address: Department of Healthcare Management, Yuanpei University, 306, Yuanpei \\ Street, Yuanpei University, Hsinchu 30015, Taiwan. E-mail: aven@mail.ypu.edu.tw
}

Received: September 23, 2012

Accepted: October 24, $2012 \quad$ Online Published: November 8, 2012

DOI : $10.5430 /$ jha.v2n1p15

URL: http://dx.doi.org/10.5430/jha.v2n1p15

\section{Abstract}

Background/Objective: The purpose of this study is to explore the causes, consequences and mediating effects of burnout as well as to highlight the correlation between burnout and related variables.

Methods: The study conducted a cross-sectional survey of 371 hospital employees in Taiwan. The questionnaire contains: job burnout, workload, role conflict, work autonomy, social support, organizational commitment and turnover intention.

Results: Four principal findings are made. First, with respect to the three components of burnout experienced by hospital employees, the most frequently reported is emotional exhaustion, being also the most problematic among hospital employees compared with employees in other industries. Second, while increased workload coupled with role conflict increases the likelihood of burnout among hospital employees, improved work autonomy and social support reduce its likelihood. Next, the study finds a direct correlation between employees' perceptions of low levels of emotional exhaustion and depersonalization and high levels of organizational commitment. In contrast, employees' perceptions of high levels of emotional exhaustion and depersonalization lead to high turnover intention. Finally, the result of the hierarchical regression analysis demonstrates a partial mediating effect of burnout in the current study.

Conclusions: These findings suggest the need for hospital management to improve their wellbeing and incentive strategies, to embark upon regular investigations into job burnout and to adopt appropriate measures to meet the professional development needs of hospital employees.

\section{Key words}

Job burnout, Hospital employee, Mediating effect

\section{Introduction}

The term burnout, coined by Freudenberger ${ }^{[1]}$, has been the focus of study for a number of researchers. Burnout has been described as a psychological syndrome of exhaustion, cynicism, and inefficacy which is experienced in response to chronic job stressors ${ }^{[2]}$. These syndromes are found to be particularly prevalent among professionals such as doctors and nurses, who work in a care service environment. Burnout consists of emotional exhaustion, depersonalization, and reduced personal accomplishment. Emotional exhaustion refers to feelings of being overextended and depleted of one's emotional 
resources. Depersonalization refers to a negative, callous or excessively detached response to other people. Reduced personal accomplishment refers to a decline in one's feeling of competence and successful achievement in one's work ${ }^{[3]}$. The operational definition that is most widely used in burnout research is the three-component model.

\subsection{The causes and consequences of job burnout}

Evaluation of the current models used to explain burnout reveals that many studies probe the factors from a variety of angles, analyzing different aspects of the causes of burnout and its impact on organizations and employees. The causes of burnout are commonly categorized into two distinct kinds: individual and organization ${ }^{[4-6]}$. Other studies have applied the conservation of resources theory to explore the causes of burnout on two particular aspects: job demands and individual resources. Job demands include role ambiguity, role conflict, pressure of events, work overload and work pressure. Individual resources include social support, recommencement contingencies, job enhancement opportunities such as automation, policymaking and autonomy ${ }^{[7-9]}$. Overall, job burnout is correlated with many job negative reactions, i.e. consequences of burnout. Conducted studies show that burnout relates to job satisfaction and organizational commitment negatively and to intention to leave positively ${ }^{[10-11]}$. Burnout tends to cause symptoms related to physiology, psychology, perception and behaviour. Pines claims that burnout leads to the demotivation of employees, absence, impaired efficiency, reduced time on the job, high turnover intention rate, increased workload and poor work performance ${ }^{[3]}$. Matin, Kalali, \& Anvari also found that employees' job burnout leads to their organizational commitment and job satisfaction mitigation ${ }^{[11]}$. On the other hand, job burnout leads into increase in employees' intention to leave. Burnout may reduce the level of work effectiveness, increase turnover intention rate and may also result in overspending on the training of new employees. Such factors are not simply a monetary cost; they represent a considerable cost in terms of human labor and time.

\subsection{Negative effects of the hospital employee burnout}

Burnout is a syndrome common in occupations where time is spent supporting other people, and has been studied extensively among medical practitioners ${ }^{[12-13]}$. Previous studies revealed that burnout could have several deteriorating effects, both for the organization and for the health-care professionals ${ }^{[13-14]}$. The accumulated evidence suggests that burnout plays an important role in both medical mistakes and sub-optimal care ${ }^{[15]}$. Theoretically, burnout is likely to cause doctors and nurses to adopt a depersonalized approach to their patients, the consequence of which is further tainting of the reputation of the hospitals. In addition, burnout may cause both doctors and nurses to become less focused on their work; an attitude that tends to cause errors. In turn, the making of mistakes leads to increased numbers of medical negligence, such as the prescribing of incorrect medicine, or diagnostic error. In view of its negative consequences, burnout is an issue that should be prioritized by hospital management. It is vital for hospitals not only to take care of patient health, but also to spare no effort with respect to the health of employees as their health has a direct effect on the operation of hospitals.

Due to the unique nature of their work and the clients they serve, hospital employees are a professional group predisposed to high burnout risk. However, the paucity of relevant research in the Taiwanese context renders our understanding of the phenomenon of burnout in Taiwan somewhat inadequate. Therefore, this study tries to fill this empirical gap in this field by answering the following research question: "How serious is the issue of burnout for hospital employees? What factors influence burnout? What are the negative effects? What are the correlations between the factors associated with burnout and their effects?”. A study that addresses these questions may provide a useful resource for government public health agencies and hospital managers to develop appropriate strategies to deal with the issue of burnout.

The researcher has developed the following hypothesis to test for the purpose of this study:

i. Hypothesis 1(H1): the job demands have a positive effect on the three components of burnout (emotional exhaustion, depersonalization, and reduced personal accomplishment).

H1-1: the workload has a positive effect on the three components of burnout 
H1-2: the role conflict has a positive effect on the three components of burnout

ii. Hypothesis 2(H2): the individual resources have a negative effect on the three components of burnout (emotional exhaustion, depersonalization, and reduced personal accomplishment).

H2-1: the work autonomy has a negative effect on the three components of burnout

H2-2: the social support has a negative effect on the three components of burnout

iii. Hypothesis 3(H3): the three components of burnout (emotional exhaustion, depersonalization, and reduced personal accomplishment) have a negative effect on employee organizational commitment (H3-1) and have a positive effect on employee turnover intention (H3-2).

iv. Hypothesis 4(H4): through the mediating effect of burnout, the job demands and resources variables further influence employee organizational commitment (H4-1) and turnover intention (H4-2).

\section{Method}

A cross-sectional questionnaire survey was conducted at three metropolitan hospitals in Taiwan to collect research data.

\subsection{Conceptual model}

Based on the burnout theory, this study proposes a hypothetic conceptual model, illustrated in Figure 1. The theoretical framework underlying the current study is shaped by the causes of burnout (independent variables), the three components of burnout (mediating variables) and the consequences of burnout (dependent variables). In this study, the causes of burnout are explored from two aspects of work of significance to the individual: job demands (workload, role conflict) and resources (autonomy in work and social support). The consequences of burnout include organizational commitment and turnover intention. Also examined is the extent to which the job demands and individual resources further influence the consequences of burnout through burnout's mediating effect. In other words, this study seeks to identify and explain the mechanism that underlies an observed relationship between independent variables and dependent variables via the inclusion of the mediator variable "burnout".

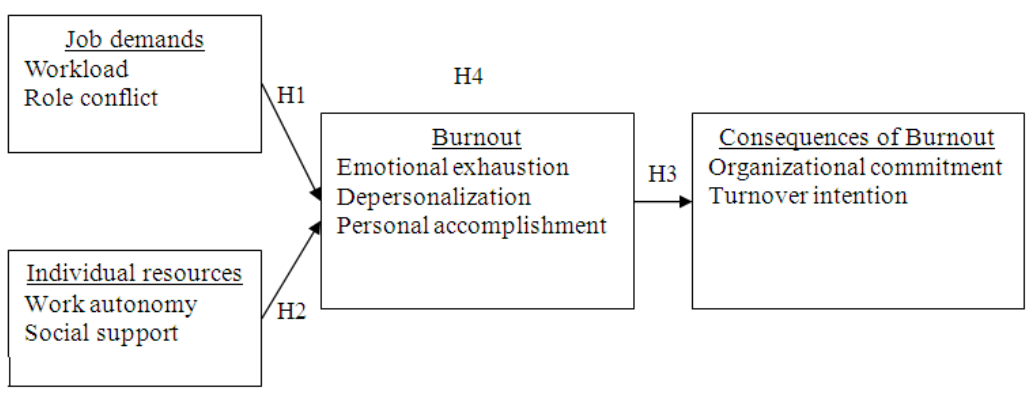

Figure 1. Proposed Conceptual Model

\subsection{Subject and sampling}

The study subjects were the employees of three metropolitan hospitals in Taiwan. Data were collected from paper questionnaires that have been filled out by full-time employees including doctors, nurses, medical technicians, and administrative staff in these hospitals. For practical reasons and to ensure as high a return rate for the questionnaire as possible, stratified purposive sampling was employed. A total of 500 questionnaires were distributed, 371 of which were returned and validated, achieving a $74.2 \%$ validity rate. Categorizing the returned sample into 4 groups, the following 
return rates were achieved: Category 1: Doctors, including internal medicine, surgery, obstetrics and gynecology, and pediatrics, returned 50 valid questionnaires (72\% valid return rate). Category 2: Nurses, including ward nursing stations and other nursing departments, returned 300 valid questionnaires (70\% valid return rate). Category 3: Medical technicians, including pharmacists, medical technologists and radiologists, returned 60 valid questionnaires (66\% valid return rate). Category 4: Administrative staff, including administrative and management personnel, returned 100 valid questionnaires (77\% valid return rate). The study was approved by the Institutional Review Board (IRB), and the employees signed the informed consent and completed the questionnaires.

The average age of study participants was 29.56, most of whom were female (84.1\%). The majority of participants had a total of four years higher education (54.4\%), followed by those with junior college education (32.6\%). In terms of marital status, the majority was single (60.4\%). With respect to work time, the majority undertook three shifts (49.6\%), followed by those with fixed daytime shifts. In terms of employment, most participants were from the nursery sector (58.5\%) and the vast majority had non-managerial status (93.3\%).

\subsection{Measures}

The questionnaire contains: job burnout, workload, role conflict, work autonomy, social support, organizational commitment and turnover intention. The job content scale developed by Karasek ${ }^{[16]}$ was utilized for the 6 questions relating to workload. The scale for the 6 work autonomy questions was borrowed from Breaugh ${ }^{[17]}$, while Rizzo, House \& Lirtzman's scale was used for the 8 role conflict questions ${ }^{[18]}$. To measure social support, the questionnaire by Liu ${ }^{[19]}$ was utilized. There were 5 questions relating to three aspects, giving a total of 15 questions. Mowday, Porter \& Steers's organizational commitment questionnaire was adopted to measure affective commitment, totaling 15 questions ${ }^{[20]}$. Turnover intention was measured with an adaptation of five of Michael \& Spector's questions ${ }^{\text {[21] }}$. All items in the above questionnaire were scored on the five-point Likert scale. The measurement for job burnout was based on Maslach's burnout inventory (MBI) ${ }^{[22]}$. MBI consisted of 5 questions on emotional exhaustion, 5 questions on depersonalization and 7 questions on reduced personal accomplishment. Each question was designed to be answered using the five-point Likert scale. Finally, the demographic variables included age, gender, marital status, education, position, professional title, years in service and working hours.

\subsection{Analytic strategy}

Following the calculation of descriptive statistics, the Pearson Product Moment Correlation was used to assess the relationship between the variables. Hierarchical Multiple Regression was used to examine the hypotheses. With respect to the test for the mediating effect of burnout, the procedures suggested by Baron \& Kenny ${ }^{[23]}$ were followed. To verify each hypothesis, the demographic variables were consistently utilized as the control variables.

\section{Results}

\subsection{Descriptive analysis of variables}

Table 1 reveals emotional exhaustion attains the highest score of the three components (with a standardized score of 67.24), indicating that this is the strongest dimension of job burnout experienced by hospital employees. The depersonalization score ranks second (with a standardized score of 59.60), which is followed by reduced personal accomplishment (with a standardized score of 49.86).

Turning to the causes of burnout, in terms of the job demands, workload achieves a standardized score of 69.03, indicating that hospital employees' workload is above average. However, according to participants, their work duties and scope were deemed reasonable. Analysis of role conflict reveals a standardized score of 56.48, indicating that this factor is not perceived as being as serious as that of workload. In terms of the individual resources, work autonomy achieves a 
standardized score of 66.43, indicating that this particular factor is regarded as satisfactory. Most employees are able to decide upon their own work approach and procedures; however, they are not able to participate in any decision making relating to work performance evaluation. Social support attains a standardized score of 71.76, demonstrating the presence of adequate social support channels for employees. The best type of social support is shown to be that from family members and colleagues.

Table 1. Descriptive statistics of the variables

\begin{tabular}{|c|c|c|c|c|}
\hline Variables & Original range & Actual range & Mean & Standardized score \\
\hline \multicolumn{5}{|l|}{ Causes of burnout } \\
\hline \multicolumn{5}{|l|}{ Job demands } \\
\hline Workload & $6-30$ & $12-30$ & 20.79 & 69.30 \\
\hline Role conflict & $8-40$ & $11-40$ & 22.58 & 56.45 \\
\hline \multicolumn{5}{|l|}{ Individual resources } \\
\hline Work autonomy & $6-30$ & $9-30$ & 19.93 & 66.43 \\
\hline Social support & $15-75$ & $27-75$ & 53.82 & 71.76 \\
\hline \multicolumn{5}{|l|}{ Burnout } \\
\hline Emotional exhaustion & $5-25$ & $6-25$ & 16.81 & 67.24 \\
\hline Depersonalization & $5-25$ & $7-23$ & 14.90 & 59.60 \\
\hline Personal accomplishment & 7-35 & $7-34$ & 17.45 & 49.86 \\
\hline \multicolumn{5}{|l|}{ Consequences of burnout } \\
\hline Organizational commitment & $15-75$ & $23-74$ & 49.58 & 66.11 \\
\hline Turnover intention & $5-25$ & $5-25$ & 16.15 & 64.60 \\
\hline
\end{tabular}

Standardized score $=($ mean $/$ total score $) \times 100$.

Turning to the consequences of burnout, organizational commitment achieves a standardized score of 66.11, indicating that hospital employees' organizational commitment is above average. The outcome of the analysis of turnover intention suggests that turnover intention is also higher than average (with a standardized score of 64.60), a finding which might be correlated to the severity of burnout. However, other factors should also be taken into account, such as level of job satisfaction and environmental variables.

\subsection{Correlation analysis of the variables}

Table 2. Correlation matrix of variables

\begin{tabular}{|c|c|c|c|c|c|c|c|c|c|c|}
\hline Variables & Mean & SD & 1 & 2 & 3 & 4 & 5 & 6 & 7 & 8 \\
\hline 1.Workload & 20.79 & 3.05 & & & & & & & & \\
\hline 2. Role conflict & 22.58 & 4.53 & $.36 * *$ & & & & & & & \\
\hline 3.Work autonomy & 19.93 & 3.31 & -.03 & -.04 & & & & & & \\
\hline 4.Social support & 53.82 & 7.87 & $-.11 *$ & $-.22 * *$ & $.31 * *$ & & & & & \\
\hline 5. Emotional exhaustion & 16.81 & 4.00 & $.62 * *$ & $.40 * *$ & $-.11 *$ & $-.12 *$ & & & & \\
\hline 6.Depersonalization & 14.90 & 2.61 & $.36 * *$ & $.39 * *$ & $-.19 * *$ & $-.21 * *$ & $.61^{* *}$ & & & \\
\hline 7. Personal accomplishment & 17.45 & 3.49 & -.02 & .02 & $-.30 * *$ & $-.32 * *$ & -.01 & .07 & & \\
\hline 8.Organizational commitment & 49.58 & 7.09 & $-.33 * *$ & $-.32 * *$ & $.21 * *$ & $.33 * *$ & $-.48 * *$ & $-.48 * *$ & $-.27 * *$ & \\
\hline 9. Turnover intention & 16.15 & 3.27 & $.27 * *$ & $.22 * *$ & -.08 & $-.12 *$ & $.43^{* *}$ & $.35^{* *}$ & -.03 & $-.56^{* *}$ \\
\hline
\end{tabular}

$* p<.05 ; * * p<.01$

From the aspect of job demands, workload positively correlates with emotional exhaustion ( $r=0.62, p<.01$ ), depersonalization $(r=0.36, p<.01)$ and turnover intention $(r=0.27, p<.01)$ (Table 2$)$. However, workload correlates negatively with organizational commitment $(r=-0.33, p<.01)$, indicating serious workload, lower a diminished level of 
employee commitment to the organization. In addition, role conflict positively correlates with emotional exhaustion $(r=0.40, p<.01)$, depersonalization $(r=0.39, p<.01)$, and negatively correlates with organizational commitment $(r=-0.32$, $p<.01)$.

From the aspect of individual resources, both of work autonomy and social support correlate negatively with the three components of job burnout, indicating that the higher the level of work autonomy and social support, the less serious the emotional exhaustion, as well as the less diminished the sense of achievement and depersonalization. In contrast, work autonomy $(r=0.21, p<.01)$ and social $\operatorname{support}(r=0.33, p<.01)$ correlate positively with organizational commitment. While social support correlates negatively with turnover intention $(r=-0.12, p<.05)$, indicating that the higher the level of social support, the greater the commitment to the organization and the lower of the intention to resign.

With respect to the three components of burnout, emotional exhaustion $(r=-0.48, p<.01)$, depersonalization $(r=-0.48, p<.01)$ and reduced personal accomplishment $(r=-0.27, p<.01)$, all negatively correlate with organizational commitment. This suggests that that the greater the degree of burnout, the lower the employee organizational commitment. In contrast, emotional exhaustion $(r=0.43, p<.01)$ and depersonalization $(r=0.35, p<.01)$ correlate positively with turnover intention.

\subsection{Verification of hypotheses}

Using Hierarchical Multiple Regression to test each hypothesis, the statistical procedures detailed earlier were followed. The relevant variables were entered into the regression model and the nominal variables were converted into dummy variables before being analyzed.

\subsubsection{The causes and the three components of burnout}

Table 3. Summary of Hierarchical Regression results for variables predicting three components of burnout

\begin{tabular}{|c|c|c|c|c|}
\hline & & Emotional exhaustion & Depersonalization & Personal accomplishment \\
\hline \multicolumn{5}{|l|}{ Control variables } \\
\hline Age & & -.01 & -.10 & -.05 \\
\hline Gender & & -.08 & & \\
\hline Education & & -.01 & & \\
\hline Marital status & & & & .04 \\
\hline \multirow{3}{*}{ Professional title } & Doctors & .01 & .02 & -.11 \\
\hline & Nurses & -.01 & .06 & .03 \\
\hline & Medical technicians & .03 & .07 & -.02 \\
\hline Years in service & & -.03 & & .01 \\
\hline Work hours & & $-.16^{* *}$ & $-.15^{*}$ & -.08 \\
\hline Position & & & & -.05 \\
\hline \multicolumn{5}{|l|}{ Job demands } \\
\hline Workload & & $.52 * *$ & $.19^{* *}$ & -.03 \\
\hline Role conflict & & $.20 * *$ & $.28 * *$ & -.03 \\
\hline \multicolumn{5}{|c|}{ Individual resources } \\
\hline Work autonomy & & -.02 & $-0.12 *$ & $-.23 * *$ \\
\hline Social support & & -.02 & -0.09 & $-.24 * *$ \\
\hline $\mathrm{R}^{2}$ & & .50 & 0.29 & .21 \\
\hline Revised $\mathrm{R}^{2}$ & & .47 & 0.25 & .16 \\
\hline$\triangle \mathrm{R}^{2}$ & & $.35^{* *}$ & $.19 * *$ & $.13^{* *}$ \\
\hline $\mathrm{F}$ & & $18.08 * *$ & $7.35^{* *}$ & $4.70 * *$ \\
\hline
\end{tabular}


In this section, the three components of burnout are used as dependent variables. In addition, the job demands and individual resources are incorporated into the regression analysis in order to test the hypotheses. With respect to emotional exhaustion, the results presented in Table 3 demonstrate that, after excluding the explanatory power of the control variables, only workload $(\beta=0.52, p<.01)$ and role $\operatorname{conflict}(\beta=0.20, p<.01)$ are predictors of emotional exhaustion. The $\triangle$ $\mathrm{R}^{2}$ is $0.35(p<.01)$, indicating that these two variables have $35 \%$ explanatory power with respect to emotional exhaustion.

In terms of depersonalization, regression analysis establishes that, after excluding the explanatory power of the control variables, workload $(\beta=0.19, p<.01)$, role conflict $(\beta=0.28, p<.01)$ and work autonomy $(\beta=-0.12, p<.05)$ have significant explanatory power with respect to depersonalization. The $\triangle \mathrm{R}^{2}$ is $0.19(p<.01)$, indicating that these three variables have 19\% explanatory power with regard to depersonalization.

In terms of reduced personal accomplishment, regression analysis reveals that, after excluding the explanatory power of the control variables, work autonomy $(\beta=-0.23, p<.01)$ and social support $(\beta=-0.24, p<.01)$ have significant explanatory power with regard to reduced personal accomplishment. The $\triangle \mathrm{R}^{2}$ is $0.13(p<.01)$, indicating that these two variables have $13 \%$ explanatory power in terms of reduced personal accomplishment.

Based on the above analyses, the current study demonstrates that when the workload is perceived to be acute, there results a greater degree of emotional exhaustion, which, in turn, leads to indifference and a sense of distance between the employee and the outside world. However, workload has not been proved to predict reduced personal accomplishment. Therefore, hypothesis H1-1 is partially supported. With respect to H1-2, the study has demonstrated that the stronger the employee's reaction to role conflict, the greater the level of emotional exhaustion and depersonalization. However, the effect of role conflict on reduced personal accomplishment is not as noticeable. Therefore, H1-2 is only partially supported.

Table 4. Summary of Hierarchical Regression results for burnout predicting organizational commitment and turnover intention

\begin{tabular}{|c|c|c|c|}
\hline & & Organizational commitment & Turnover intention \\
\hline \multicolumn{4}{|l|}{ Control variables } \\
\hline \multicolumn{2}{|l|}{ Age } & .09 & -.05 \\
\hline \multicolumn{2}{|l|}{ Gender } & .07 & $-.14 *$ \\
\hline \multicolumn{2}{|l|}{ Education } & .05 & .04 \\
\hline \multicolumn{2}{|l|}{ Marital status } & .01 & -.06 \\
\hline \multirow{3}{*}{ Professional title } & Doctors & -.09 & .12 \\
\hline & Nurses & -.08 & .00 \\
\hline & Medical technicians & -.07 & .06 \\
\hline \multicolumn{2}{|l|}{ Years in service } & .06 & -.06 \\
\hline \multicolumn{2}{|l|}{ Work hours } & .06 & -.07 \\
\hline \multicolumn{2}{|l|}{ Position } & .07 & -.03 \\
\hline \multicolumn{4}{|l|}{ Burnout } \\
\hline \multicolumn{2}{|c|}{ Emotional exhaustion } & $-.25 * *$ & $.27 * *$ \\
\hline \multicolumn{2}{|l|}{ Depersonalization } & $-.27 * *$ & $.16^{*}$ \\
\hline \multicolumn{2}{|c|}{ Personal accomplishment } & $-.23 * *$ & -.05 \\
\hline \multicolumn{2}{|c|}{$\mathrm{R}^{2}$} & .41 & .22 \\
\hline \multicolumn{2}{|l|}{ Revised $\mathrm{R}^{2}$} & .38 & .18 \\
\hline \multicolumn{2}{|l|}{$\triangle \mathrm{R}^{2}$} & $.24 * *$ & $.26 * *$ \\
\hline \multicolumn{2}{|l|}{$\mathrm{F}$} & $13.52^{* * *}$ & $5.60^{* *}$ \\
\hline
\end{tabular}

$* p<.05 ; * * p<.01$ 
Examination of the impact of individual resources on job burnout has revealed that the higher the employee's work autonomy, the less likely they are to distance themselves from others. Low employee work autonomy promotes self-doubt about work ability. In turn, such doubt leads to the tendency for employees to undervalue their collaborative achievements with others. However, the extent to which work autonomy can explain emotional exhaustion is limited. Therefore, H2-1 is partially supported. In addition, social support has been found not to be a significant predictor of emotional exhaustion and depersonalization.

\subsubsection{Burnout and its consequences}

As shown in Table 4, with respect to organizational commitment, after excluding the explanatory power of the control variables, emotional exhaustion, depersonalization and reduced personal accomplishment are all significant, with their respective $\beta$ values being $-0.25(p<.01),-0.27(p<.01)$ and $-0.23(p<.01)$ and $\triangle \mathrm{R}^{2}$ being 0.24 . Therefore, H3-1 is supported.

In terms of turnover intention (Table 4), after excluding the explanatory power of the control variables, emotional exhaustion and depersonalization are found to be significant predictors of turnover intention, with $\beta$ values of $0.27(p<.01)$ and $0.16(p<.05)$ as well as $\triangle \mathrm{R}^{2}$ of 0.26 . However, reduced personal accomplishment is found not to be a significant predictor of turnover intention. Therefore, H3-2 is partially supported.

Table 5. Summary of Hierarchical Regression results for variables predicting organizational commitment: three components of burnout as mediators

\begin{tabular}{|c|c|c|c|c|}
\hline \multirow{2}{*}{\multicolumn{2}{|c|}{ Control variables }} & \multirow{2}{*}{ Model 1} & \multirow[t]{2}{*}{ Model 2} & \multirow{2}{*}{ Model 3} \\
\hline & & & & \\
\hline Age & & .18 & .17 & .13 \\
\hline Gender & & .06 & .06 & .06 \\
\hline Marital status & & .01 & .02 & .01 \\
\hline Education & & .05 & .07 & .06 \\
\hline \multirow{3}{*}{ Professional title } & Doctors & -.02 & -.13 & $-.13^{*}$ \\
\hline & Nurses & -.09 & $-.18^{*}$ & $-.16^{*}$ \\
\hline & Medical technicians & -.09 & $-.124 *$ & -.11 \\
\hline Position & & .04 & .02 & .03 \\
\hline Years in service & & .04 & .10 & .09 \\
\hline Work hours & & $.19 * *$ & .08 & .03 \\
\hline \multicolumn{5}{|c|}{ Independent variables } \\
\hline Workload & & & $-.13^{*}$ & .01 \\
\hline Role conflict & & & $-.16^{*}$ & -.07 \\
\hline Work autonomy & & & $.19 * *$ & $.13^{*}$ \\
\hline Social support & & & $.24 * *$ & $.19 * *$ \\
\hline \multicolumn{5}{|c|}{ Mediating variables } \\
\hline Emotional exhau & & & & $-.21^{* *}$ \\
\hline Depersonalizatio & & & & $-.20 * *$ \\
\hline Personal accomp & hment & & & $-.14^{* *}$ \\
\hline $\mathrm{R}^{2}$ & & .17 & .38 & .47 \\
\hline Revised $\mathrm{R}^{2}$ & & .14 & .345 & .43 \\
\hline$\triangle \mathrm{R}^{2}$ & & $.17^{* *}$ & $.21^{* *}$ & $.09 * *$ \\
\hline $\mathrm{F}$ & & $5.13 * *$ & $11.09 * *$ & $13.21 * *$ \\
\hline
\end{tabular}

${ }^{*} p<.05 ; * * p<.01$ 


\subsubsection{The mediating effect of burnout}

This section examines whether the variables of job demands and individual resources, via the mediating effect of burnout, have an impact on employees’ organizational commitment and turnover intention.

With respect to organizational commitment, the results are presented in Table 5. Model 2 indicates that the respective $\beta$ values for workload, role conflict, work autonomy and social support are $-0.13(p<.05),-0.16(p<.01), 0.19(p<.01)$ and 0.24 ( $p<.01)$, and $\triangle \mathrm{R}^{2}$ is $21 \%$. Model 3 incorporates both independent variables and mediating variables into the model, revealing that the explanatory power of work autonomy and social support with respect to organizational commitment tends to decline due to the presence of the three components of burnout. This is exemplified in the reduction of the $\beta$ value for work autonomy from $0.19(p<.01)$ to $0.13(p<.05)$ and the $\beta$ value for social support from $0.24(p<.01)$ to $0.19(p<.05)$. In addition, the explanatory power of workload and role conflict is not significant, and the reduction of $\triangle \mathrm{R}^{2}$ from $21 \%$ to 9\%. These results indicate that the impact of independent variables on organizational commitment has been generated via the partial mediating effect of the three components burnout. Thus, H4-1 hypothesis is partially supported.

Table 6. Summary of Hierarchical Regression results for variables predicting: three components of burnout as mediators

\begin{tabular}{|c|c|c|c|c|}
\hline & & Model 1 & Model 2 & Model 3 \\
\hline \multicolumn{5}{|l|}{ Control Variables } \\
\hline \multicolumn{2}{|l|}{ Age } & -.12 & -.09 & -.06 \\
\hline \multicolumn{2}{|l|}{ Gender } & $-.15^{*}$ & $-.16^{*}$ & $-.14 *$ \\
\hline \multicolumn{2}{|l|}{ Marital status } & -.07 & -.08 & -.05 \\
\hline \multicolumn{2}{|l|}{ Education } & .04 & .03 & .04 \\
\hline \multirow{3}{*}{ Professional title } & Doctors & .12 & $.16^{*}$ & .14 \\
\hline & Nurses & .04 & .04 & .03 \\
\hline & Medical technicians & .09 & .10 & .08 \\
\hline \multicolumn{2}{|l|}{ Position } & .02 & -.01 & -.01 \\
\hline \multicolumn{2}{|l|}{ Years in service } & -.04 & -.07 & -.07 \\
\hline \multicolumn{2}{|l|}{ Work hours } & $-.19 * *$ & -.13 & -.07 \\
\hline \multicolumn{5}{|c|}{ Independent variables } \\
\hline \multicolumn{2}{|l|}{ Workload } & & $.14^{*}$ & -.01 \\
\hline \multicolumn{2}{|l|}{ Role conflict } & & $.15^{*}$ & .06 \\
\hline \multicolumn{2}{|l|}{ Work autonomy } & & -.05 & -.05 \\
\hline \multicolumn{2}{|l|}{ Social support } & & -.06 & -.07 \\
\hline \multicolumn{5}{|c|}{ Mediating variables } \\
\hline \multicolumn{2}{|c|}{ Emotional exhaustion } & & & $.25^{* *}$ \\
\hline \multicolumn{2}{|l|}{ Depersonalization } & & & .13 \\
\hline \multicolumn{2}{|c|}{ Personal accomplishment } & & & -.08 \\
\hline \multicolumn{2}{|l|}{$\mathrm{R}^{2}$} & .09 & .16 & .23 \\
\hline \multicolumn{2}{|l|}{ Revised $\mathrm{R}^{2}$} & .06 & .12 & .18 \\
\hline \multicolumn{2}{|l|}{$\triangle \mathrm{R}^{2}$} & $.09 * *$ & $.07 * *$ & $.07 * *$ \\
\hline \multicolumn{2}{|l|}{$\mathrm{F}$} & $2.51 * *$ & $3.53 * *$ & $4.61^{* *}$ \\
\hline
\end{tabular}

$* p<.05 ; * * p<.01$

In terms of turnover intention , as shown in Model 2 of Table 6, after excluding the explanatory power of the control variables, the respective $\beta$ values for workload and role conflict are found to be significant at $0.14(p<.05)$ and $0.15(p<.05)$, and $\triangle \mathrm{R}^{2}$ is $7 \%$. In Model 3, both the independent variables and mediating variables are entered into the model. After excluding the explanatory power of the control variables, workload and role conflict are found to be predictors of turnover intention; however, their power is reduced by the mediating effect of the three components of burnout. As a consequence, 
the effect of workload and role conflict is not particularly apparent. In contrast, emotional exhaustion is found to be a significant predictor of turnover intention $(\beta=0.25, p<.01)$. Based on the above results, it is evident that the effects of the independent variables on turnover intention are mediated by emotional exhaustion. Thus, hypothesis H4-2 is partially supported.

\section{Discussion}

\subsection{Discussion on burnout}

\subsubsection{Hospital employee burnout}

Hospitals provide a broad range of services vital for human health and wellbeing. Due to the uniqueness of their work, hospital employees tend to undertake excessive overtime work, which places unreasonable pressure on their interpersonal relationships. Ironically, the very nature of hospitals as continually operational places for the improvement of health on a wide variety of levels leads to a tendency for hospital employees to suffer from physical and mental fatigue as well as job burnout. Such burnout impacts not only on employees’ physical and psychological wellbeing, but also on their attitudes and behaviors.

In the present study, emotional exhaustion is found to be perceived by hospital employees as the most important dimension of burnout. This is followed by depersonalization, with reduced personal accomplishment ranking least important. In comparison to the findings of similar studies in Taiwan ${ }^{[24-26]}$, job burnout in this study is found to be higher. This result is worthy of the attention of hospital management and health administrative agencies. In addition, it merits further study to ascertain whether environmental changes in the healthcare industry have given rise to the increase in job burnout among hospital employees.

Some studies compared the burnout situations of health industry employee and found that there was a significant difference in the various occupational categories. ${ }^{[27-28]}$. This study compares job burnout among different types of hospital employee, including doctors, nurses, medical technicians and administrative staff. The result shows that the three components of burnout are statistically significant in these professional categories. The a posteriori comparison shows that emotional exhaustion and depersonalization among doctors is significantly higher than among nurses; while reduced personal accomplishment among administrative staff is significantly higher than among doctors. This highlights the seriousness of emotional exhaustion and depersonalization among doctors. The nature of the work and the determination of role relationships may be factors in reduced personal accomplishment among both nurses and administrative staff.

\subsubsection{The impact of job demands on burnout}

The current study provides evidence for the claim that heavier workloads generate higher levels of emotional exhaustion for employees. Such exhaustion, in turn, creates distance for employees from others as well as a sense of indifference towards the external world. This finding echoes the results of Lee \& Ashforth ${ }^{[8]}$, who used the theory of resource conservation to conduct a meta-analysis of 61 studies published between 1982 and 1994. In terms of the impact of burnout, the present study finds that job demands, including workload and workplace stress, are the chief and direct cause of emotional exhaustion and depersonalization. In light of this finding, in order to reduce the likelihood of emotional exhaustion and depersonalization, employee workload and hours should be reduced; moreover, additional remuneration for the overtime work should be provided.

Piko reported a correlation between role conflict and burnout in nurses ${ }^{[29]}$. Tunc \& Kutanis proposed role conflict was strongly associated with emotional exhaustion and depersonalization in healthcare professionals ${ }^{[9]}$. This study also finds that the more acutely employees sense role conflict, the greater the likelihood of their experiencing emotional exhaustion and depersonalization. However, the issue of role conflict among hospital employees is not serious. One probable reason 
for this is that hospital employees are engaged in professional work with clearly defined roles; this is especially true of doctors and medical technicians. As a consequence, they are able to perform their roles better and to meet the expectations of their patients.

\subsubsection{The impact of individual resources on burnout}

Schaufeli \& Bakker discovered that burnout could be predicted by job demands and deprivation of resources ${ }^{[10]}$. When dealing with job demands as well as lack of work control and social support, an employee will be more likely to experience burnout. Foqarty et al. maintains that burnout is the cumulative effect of pressure ${ }^{[30]}$. Although the source of pressure may be itself rather low, the cumulative effect will exceed the employee resources, resulting in negative work effects for the employee through burnout. This study provides partial empirical support for the claim made by these two scholars.

According to Lee $\&$ Ash forth ${ }^{[8]}$, work support, which includes managerial support and family support, is an additional employee resource. Employees seek sustainable resources to compensate for the loss of resources caused by a wide variety of variables to prevent a resource shortage crisis. What this study also demonstrates is that hospital employees' perceptions of heightened social support tend not to contribute to reduced personal accomplishment. As such, social support would appear to have an ameliorating effect on reduced personal accomplishment caused by burnout. With the full support of managers and/or family members, the individual can regain their self-efficacy, and enhance their concept of self as well as their sense of fulfillment at work. However, social support does not reach significance level as a predictor of the two components of emotional exhaustion and depersonalization.

\subsubsection{The impact of burnout on job negative reactions}

Several researches are done to study the impacts of burnout on such variables as the intention to leave and organizational commitment in different jobs ${ }^{[11]}$. This study obtains similar results using data from hospital employees. Organizational commitment, being the individual loyalty and contribution to an organization, not only influences that individual level of input into the organization, but also represents their attitudes and preferences with respect to their role in the organization. Such a connection is valuable not only to the individual, but also to the organization ${ }^{[21]}$. Therefore, burnout resulting in lower organizational commitment has a considerable impact on the effectiveness of the organization.

\subsubsection{The mediating effect of burnout}

Earlier research suggests that burnout has a mediating position between organizational factors influencing work conditions of employees and outcome variables such as organizational commitment, turnover intentions, job satisfaction, work performance, and health problems ${ }^{[10,30]}$. A number of studies support the hypothesis that several organizational aspects of nursing, encompassing the six areas of work life, have a direct impact on feelings of burnout, especially emotional exhaustion and depersonalization ${ }^{[31]}$. The results of this study indicate that job demands and resources influence organizational commitment through the partial mediating effect of burnout. The influence of workload and role conflict on turnover intention is achieved through the complete mediating effect of emotional exhaustion. Again, this result indicates that job burnout indeed mediates some of the negative behaviors of employees. In particular, increased workload and severe role conflict for hospital employees tend to result in emotional exhaustion, triggering a rise in employee turnover intention. This observation merits serious attention from hospital management and human resource departments.

\subsection{Conclusion}

The results of this study demonstrate the importance of hospital management teams and academics addressing the issue of job burnout. Obviously, the negative consequences of job burnout are too costly for organizations. This is particularly important in view of the current situation in Taiwan, where the entire healthcare industry has undergone dramatic changes and where profound reformation of public health and insurance regulations as well as healthcare policies is underway. These changes have resulted in unprecedented managerial challenges for Taiwanese hospitals. It is not only hospitals that are facing challenges; hospital employees are facing similar challenges. A number of issues have been uncovered in Taiwan in recent years; for example, the uneven distribution of doctors in different departments (surgery and gynecology 
departments have been unable to employ resident doctors). In addition, there has been a severe drain of nurses from hospitals (due to the excessively low number of nurses working as clinical nurses). These issues have now become top priority for hospital management. However, if the issue of burnout is not adequately addressed, the quality of the entire healthcare system will be compromised.

This study advises hospital management to consider improving the work conditions of hospital employees and to introduce motivational strategies; to undertake regular investigations into the issue of burnout; and to take measures to satisfy employees' professional development needs. In addition, employees should learn strategies for coping with as well as reducing stress levels. They should also seek social support and broaden their social connection channels.

\subsection{Limitations}

Two limitations should be considered when interpreting the findings of this study. First, due to limited manpower and time, in this study, purposive sampling was adopted, which might have an effect on the external validity of the findings. In addition, as the research tool in the study is self-reporting questionnaire, which elicits sensitive information such as organizational commitment and turnover intention, there is the risk of a degree of common method bias. In an attempt to maximize the validity of the data, in the study, the guarantee of anonymity with respect to the questionnaire and the fact that the data would be used exclusively for research purposes only were both highlighted. By increasing the respondents' willingness to provide honest answers in this way, the reliability of the research results has been improved.

\section{References}

[1] Freudenberger HJ. Staff burnout. J Soc Issues.1974; 30(1): 159-165. http://dx.doi.org/10.1111/j.1540-4560.1974.tb00706.x

[2] Maslach C. Different perspectives on job burnout. Contemporary Psychology: APA Review of Books. 2004; 49(2): 168-170.

[3] Maslach C. Burnout: A multidimensional perspective. In: Schaufeli WB, Maslach C, Marek T. eds. Professional burnout: Recent developments in theory and research. Washington, DC: Taylor \& Francis; 1993: 19-32.

[4] Maslach C, Schaufeli WB, Leiter MR. Job burnout. Annu Rev Psychol. 2001; 52: 397-422. PMid:11148311 http://dx.doi.org/10.1146/annurev.psych.52.1.397

[5] Jawahar IM, Stone TH, Kisamore J L. Role conflict and burnout: the direct and moderating effects of political skill and perceived organizational support on burnout dimensions. Int J Stress Manag. 2007; 14: 142-59.

http://dx.doi.org/10.1037/1072-5245.14.2.142

[6] Santavirta N, Solovieva S, Theorell T. The association between job strain and emotional exhaustion in a cohort of 1,028 Finnish teachers. Br. J. Educ. Psychol. 2007; 77: 213-28. PMid:17411496 http://dx.doi.org/10.1348/000709905X92045

[7] Cordes CL, Dougherty TW. A review and an integration of research on job burnout. Acad Manage Rev. 1993; 18: 621-656.

[8] Lee RT, Ashforth BE. A meta-analytic examination of the correlates of the three dimensions of job burnout. J Appl Psychol. 1996; 81: 123-133. http://dx.doi.org/10.1037/0021-9010.81.2.123

[9] Tunc T, Kutanis RO. Role conflict, role ambiguity, and burnout in nurses and physicians at a university hospital in Turkey. Nurs Health Sci. 2009; 11(4): 410-416. PMid:19909450 http://dx.doi.org/10.1111/j.1442-2018.2009.00475.x

[10] Schaufeli W, Bakker AB. Job demands, job resources, and their relationship with burnout and engagement. J Organ Behav. 2004; 25: 293-315. http://dx.doi.org/10.1002/job.248

[11] Matin HZ, Kalali NS, Anvari MRA. Do demographic variables moderate the relationship between job burnout and its consequences? Iran J Manag Stud. 2012; 5(1): 47-62.

[12] Wu S, Zhu W, Wang Z, Wang M, Lan Y. Relationship between burnout and occupational stress among nurses in China. J Adv Nurs. 2007; 59(3): 233-239. PMid:17590211 http://dx.doi.org/10.1111/j.1365-2648.2007.04301.x

[13] Sahraian A, Fazelzadeh A, Mehdizadeh AR, Toobaee SH .Burnout in hospital nurses: a comparison of internal, surgery, psychiatry and burns wards. Int Nurs Rev. 2008; 55(1): 62-67. PMid:18275537 http://dx.doi.org/10.1111/j.1466-7657.2007.00582.x

[14] Xianyu Y, Lambert VA. Investigation of the relationships among workplace stressors, ways of coping and mental health of Chinese head nurses. Nurs Health Sci. 2006; 8(3): 147-155. PMid:16911174 http://dx.doi.org/10.1111/j.1442-2018.2006.00281.x

[15] Montgomery A, Panagopoulou E, Kehoe I, Valkanos E. Connecting organisational culture and quality of care in the hospital: is job burnout the missing link?. J Health Organ Manag. 2011; 25(1): 108-123. PMid:21542465 
[16] Karasek R, Brisson C, Kawakami N, Houtman I, Bongers P, Amick B. The Job Content Questionnaire (JCQ): an instrument for internationally comparative assessments of psychosocial job characteristics. J Occup Health Psych. 1998; 3: 322-55. http://dx.doi.org/10.1037/1076-8998.3.4.322

[17] Breaugh JA. The measurement of work autonomy. Human Relations. 1985; 38(6): 551-570. http://dx.doi.org/10.1177/001872678503800604

[18] Rizzo JR, House RJ, Lirtzman SI. Role conflict and ambiguity in complex organizations. Adm Sci Q. 1970; 5: 150-163. http://dx.doi.org/10.2307/2391486

[19] Liu. The study of social support and life adjustment for the elderly in Su-Lin city, Taipei County [dissertation]. Taipei, Taiwan: National Taiwan Normal University; 2009.

[20] Mowday RT, Porter LW, Steers RM. Employee-organization linkages: The psychology of commitment, absenteeism, and turnover. New York: Academic Press; 1982.

[21] Michaels CE, Spector PE. Cause of employee turnover. A test of the Mobley, Giffeth, Hand and Meglino Model. J Appl Psychol. 1982; 67(1): 53-59. http://dx.doi.org/10.1037/0021-9010.67.1.53

[22] Maslach C, Jackson SE. Maslach Burnout Inventory. Palo Alto, CA: Consulting Psychologists Press; 1981.

[23] Baron RM, Kenny DA. The moderator-mediator variable distinction in social psychological research: Conceptual, strategic, and statistical considerations. J Pers Soc Psychol. 1986; 51: 1173-1182. http://dx.doi.org/10.1037/0022-3514.51.6.1173

[24] Chan SN. A Study on Occupational Job Burnout of Female Nurses in the Hospital [dissertation]. Taichung, Taiwan: Asia University; 2004.

[25] Wang SH. Medical practitioners work stress, job satisfaction and burnout of the study [dissertation]. Taichung, Taiwan: Tokai University; 2001.

[26] Huang YW. A multi-level research of physicians’ job burnout [dissertation]. Hsinchu, Taiwan: Yuanpei University; 2012.

[27] Ghodse H, Galea S. Misuse of drugs and alcohol. In Cox J, King J, Hutchinson A, McAvoy P. eds. Understanding Doctors' Performance. Radcliffe Publishing, Oxford; 2006: 38-48.

[28] Thorsen V C, Tharp ALT, MeguidT. High rates of burnout among maternal health staff at a referral hospital in Malawi: A cross-sectional study. BMC Nurs. 2011; 10(1): 1-7. PMid:21605379 http://dx.doi.org/10.1186/1472-6955-10-9

[29] Piko BF. Burnout, role conflict, job satisfaction and psychological health among Hungarian health care staff: a questionnaire survey. Int J Nurs Stud. 2006; 43: 311-318. PMid:15964005 http://dx.doi.org/10.1016/j.ijnurstu.2005.05.003

[30] Foqarty TJ, Singh J, Rhoads GK, Moore RK. Antecedents and consequences of burnout in accounting: Beyond the role stress model. Behav Res Account. 2000; 12: 31-67.

[31] Van Bogaert P, Meulemans H, Clarke S, Vermeyen K, Van de Heyning P .Hospital nurse practice environment, burnout, job outcomes and quality of care: test of a structural equation model. J Adv Nurs. 2009; 65(10): 2175-2185. PMid:20568322 http://dx.doi.org/10.1111/j.1365-2648.2009.05082.x 